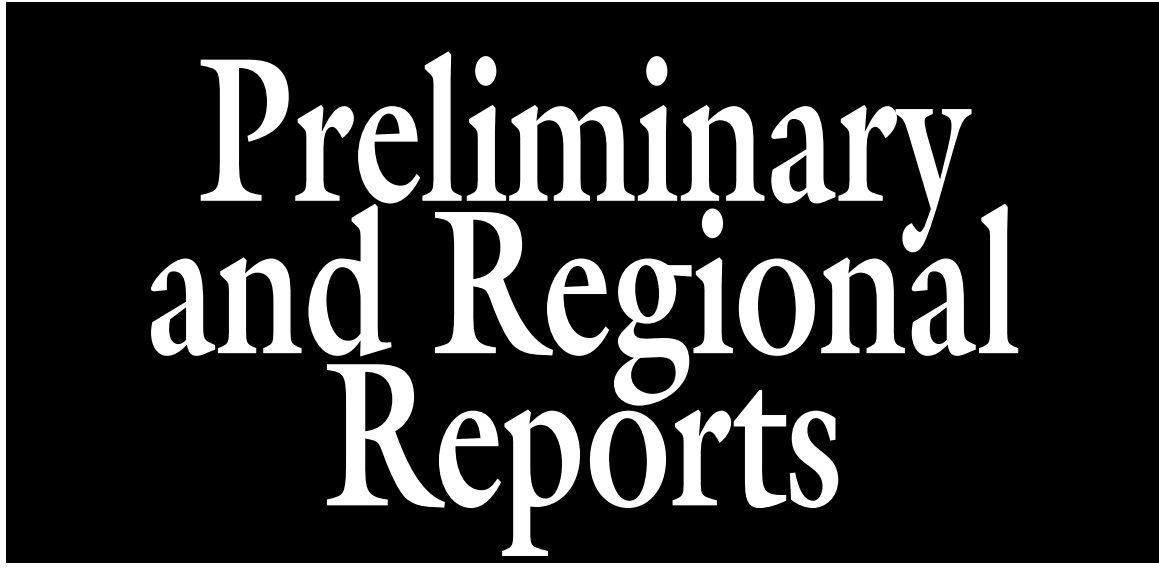

\section{Submist is Effective for Propagation of Korean Lilac and Inkberry by Stem Cuttings}

\author{
Bryan J. Peterson ${ }^{1}$, Stephanie E. Burnett, and Olivia Sanchez
}

AdDITIONAL INDEX wORDs. adventitious roots, aeroponics, overhead mist, Syringa pubescens ssp. patula, Ilex glabra

SUMMARY. Although overhead mist revolutionized the propagation industry, it does suffer from potential drawbacks that include the application of large volumes of water, potentially unsanitary conditions, irregular misting coverage, and leaching of foliar nutrients. We explored the feasibility of submist as an alternative as it might avoid these problems by applying water exclusively from below the cutting, which is inserted basally into an enclosed rooting chamber. We propagated cuttings of korean lilac (Syringa pubescens ssp. patula) and inkberry (Ilex glabra) using both overhead mist and submist to compare effectiveness of the systems. Cuttings of korean lilac were wounded and dipped basally into $8000 \mathrm{mg} \cdot \mathrm{L}^{-1}$ of the potassium salt of indole-3-butyric acid (K-IBA), and those in the overhead mist systems were inserted into coarse perlite. Cuttings of inkberry were wounded and treated with $5000 \mathrm{mg} \cdot \mathrm{L}^{-1} \mathrm{~K}-\mathrm{IBA}$, and those in the overhead mist systems were inserted into 50:50 peat:perlite (by vol). Cuttings of korean lilac in the submist systems produced more than twice as many roots as cuttings in the overhead mist systems, with roots more than 2.6 times the length. Similarly, cuttings of inkberry in the submist systems produced more than three times the root counts and root lengths as cuttings in the overhead mist systems. For korean lilac, root dry weights averaged $58 \mathrm{mg}$ for cuttings in the submist system, compared with only $18 \mathrm{mg}$ among cuttings receiving overhead mist. Likewise, root dry weights averaged 70 and $7 \mathrm{mg}$ for cuttings of inkberry propagated by submist and overhead mist, respectively. Rooted cuttings of korean lilac transplanted well into a soilless substrate, where they more than tripled their root biomass to $218 \mathrm{mg}$ (vs. $59 \mathrm{mg}$ for cuttings transplanted from overhead mist). We did not evaluate transplant performance of inkberry. Our results show that submist systems might merit consideration for the propagation of woody plants by leafy stem cuttings.

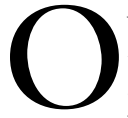
verhead mist revolutionized the propagation industry by providing a reliable means to manage transpirational water loss by leafy stem cuttings. This system slows transpiration of cuttings primarily by decreasing leaf temperatures through evaporative cooling from the leaf surface (Hartmann et al., 2011). However, overhead mist has potential drawbacks, including the use of large volumes of water, potentially unsanitary conditions created by persistent the depression of root-zone temperatures by evaporative cooling (Hartmann et al., 2011), nonuniform misting coverage, leaching of foliar nutrients (Preece, 2003), and the need to extensively acclimate cuttings to a lowhumidity, mist-free environment.

A potential alternative to overhead mist is submist aeroponics, which relies on the application of mist from below the cutting, to the base of the stem inserted into an enclosed chamber. Several systems are available on the consumer market for use by home gardeners, but their potential for propagation of woody ornamental plants has not been well researched. Recently, Peterson et al. (2018) found that submist aeroponics was superior to overhead mist for the propagation of 'Wizard Mix' coleus (Plectranthus scutellarioides) by stem cuttings. Coleus rooted in submist systems produced more than three times as many primary roots, with maximum root lengths six times greater, and root dry weights eight times those of cuttings propagated in overhead mist systems (Peterson et al., 2018). To build upon on these findings, we sought to test submist systems as alternatives to overhead mist for the propagation of woody ornamental plants by stem cuttings.

Korean lilac and inkberry are two species grown commercially in the nursery industry. According to Dirr and Heuser (2006), korean lilac can be propagated reliably from softwood stem cuttings treated with $8000 \mathrm{mg} \cdot \mathrm{L}^{-1}$ indole-3-butyric acid (IBA). Although they do not specify a substrate for this species, Dirr and Heuser (2006) suggest perlite as a suitable rooting medium for common lilac (Syringa vulgaris). Inkberry can be propagated from semihardwood cuttings during late summer and fall, for which Dirr and Heuser (2006) suggest $1000-8000 \mathrm{mg} \cdot \mathrm{L}^{-1}$ IBA and the use of a 50:50 (by vol) peat:perlite substrate.

Our objective was to test the feasibility of submist aeroponics as an alternative to overhead mist for

\begin{tabular}{llll}
\hline $\begin{array}{l}\text { Units } \\
\text { To convert U.S. to SI, } \\
\text { multiply by }\end{array}$ & U.S. unit & SI unit & $\begin{array}{l}\text { To convert SI to U.S., } \\
\text { multiply by }\end{array}$ \\
\hline 3.7854 & gal & $\mathrm{L}$ & 0.2642 \\
2.54 & inch(es) & $\mathrm{cm}$ & 0.3937 \\
28,350 & $\mathrm{oz}$ & $\mathrm{mg}$ & $3.5274 \times 10^{-5}$ \\
1 & $\mathrm{ppm}$ & $\mathrm{mg} \cdot \mathrm{L}^{-1}$ & 1 \\
14.7868 & tablespoon $(\mathrm{s})$ & $\mathrm{cm}^{3}$ & 0.0676 \\
$\left({ }^{\circ} \mathrm{F}-32\right) \div 1.8$ & ${ }^{\circ} \mathrm{F}$ & ${ }^{\circ} \mathrm{C}$ & $\left({ }^{\circ} \mathrm{C} \times 1.8\right)+32$
\end{tabular}

Hortlechnology · June 2018 28(3) 
propagation of woody plants by stem cuttings. We conducted separate experiments with korean lilac and inkberry to determine whether measures of rooting differed between the two systems. For korean lilac, we also investigated whether the plants from each system transplanted successfully into a soilless medium and produced additional root biomass.

\section{Materials and methods}

Plant materials. On 13 July 2016, we collected 100 semihardwood terminal cuttings of korean lilac averaging $6 \mathrm{~cm}$ in length from three plants of a single, unidentified cultivar growing in full sun, without regular irrigation or fertilizer application, on the University of Maine Campus in Orono, ME. Each cutting comprised a stem with two nodes, with the leaves removed from the lower node. In a second experiment started on 14 Oct. 2016, we collected 100 semihardwood terminal cuttings of inkberry averaging $10 \mathrm{~cm}$ in length from two plants of a single clone growing in full sun in the Lyle E. Littlefield Ornamentals Trial Garden in Orono, $\mathrm{ME}$, without regular irrigation or fertilizer application. Each cutting consisted of five to eight nodes, with leaves removed from the basal 1 inch of stem. For each experiment, cuttings were wounded with a razor blade by gently scraping the bark on one side of the stem near the basal end. Cuttings of korean lilac received a treatment of $8000 \mathrm{mg} \cdot \mathrm{L}^{-1} \mathrm{~K}-\mathrm{IBA}$ (Sigma Chemical Co., St. Louis, MO) and cuttings of inkberry received $5000 \mathrm{mg} \cdot \mathrm{L}^{-1} \mathrm{~K}-\mathrm{IBA}$. The basal $l$ inch of all cuttings were dipped for $10 \mathrm{~s}$ in K-IBA dissolved in water, after which the applied solution was allowed to dry before cuttings were inserted into overhead mist or submist aeroponics systems.

\footnotetext{
School of Food and Agriculture, University of Maine 5722 Deering Hall, Orono, ME 04469

Maine Agricultural and Forest Experiment Station Publication Number 3594. We thank the Maine Food and Agriculture Center for providing funding through a Horticulture Research Grant. This project was supported by the USDA National Institute of Food and Agriculture, Hatch Project \#ME021423 and \#ME021614, and a Multistate Grant \#ME031401 through the Maine Agricultural \& Forest Experiment Station.

We thank Sun Gro for providing growing media. Thank you to Bradly Libby for technical support.

${ }^{1}$ Corresponding author. E-mail: bryan.j.peterson@ maine.edu.

https://doi.org/10.21273/HORTTECH03970-18
}

Experimental design. The design of each experiment comprised five blocks, each containing an overhead mist system and a submist aeroponic system, which served as the experimental units $(n=5 ; N=10)$. Ten cuttings serving as subsamples were inserted into each system within each block. The media selected for the overhead mist systems were coarse perlite (Whittemore Co., Lawrence, MA) for propagation of korean lilac and 50:50 perlite:peatmoss (Fafard Canadian Sphagnum; Sun Gro Horticulture, Agawam, MA) for propagation of inkberry. In each experiment, the cuttings were inserted basally into open trays $(40 \times 40 \times 13 \mathrm{~cm})$ of media.

Traditional overhead mist systems consisted of a single low-pressure nozzle (Vibro-Spreader; Rain-Tal, Or-Akiva, Israel) mounted on the top of a $57-\mathrm{cm}$-tall polyvinyl chloride (PVC) riser. Mist was turned on for $10 \mathrm{~s}$ every $10 \mathrm{~min}$ using a normally closed 24-V AC solenoid valve (Netafim, Fresno, CA) connected to an electronic timer (Gemini 6A; Phytotronics, Earth City, MO). Each submist system consisted of 16 mist nozzles (Botanicare $330^{\circ}$ Micro Sprayer; American Agritech, Chandler, AZ) tapped into to a $3 / 4$-inch PVC manifold with dimensions of $56 \times$ $33 \mathrm{~cm}$ within a plastic tub with a dimension of $74 \times 52 \times 37 \mathrm{~cm}$ (Commander 27-Gallon Black Tote; Centrex Plastics, Findlay, $\mathrm{OH})$. Hooked to the manifold was a submersible pump (Eco-plus ECO-396; Sunlight Supply, Vancouver, WA) connected to a timer (Titan Controls Apollo 12 Timer; Sunlight Supply), which operated the pump for $10 \mathrm{~s}$ every $10 \mathrm{~min}$. The cuttings were secured within $1 / 4$-inch holes drilled in a $1 / 2$-inchthick sheet of rigid foam insulation placed in the lid. The level of water was checked daily; more water was added to maintain a uniform volume $(32 \mathrm{~L})$ throughout the experiment.

Propagation systems were located under $25 \%$ mylar shadecloth in a greenhouse covered with triple-layer polycarbonate glazing. Temperature was measured using a Watchdog 1450 micro station with radiation shield (Spectrum Technologies, Aurora, IL) located under the shadecloth, near the height of the cuttings. The average daily temperature while rooting korean lilac was $29.6{ }^{\circ} \mathrm{C}$, with a maximum instantaneous reading of $46.9{ }^{\circ} \mathrm{C}$. The average daily temperature while rooting inkberry was $20.6{ }^{\circ} \mathrm{C}$, with a maximum of $32.3^{\circ} \mathrm{C}$. Photosynthetically active radiation $(P A R)$ under the shadecloth was measured using a quantum light sensor attached to the same data logger, and daily light integral (DLI) was calculated from this data by multiplying $\mu \mathrm{mol} \cdot \mathrm{m}^{-2} \cdot \mathrm{s}^{-1}$ by $1,000,000$ and dividing this number by 86,400 to obtain $\mathrm{mol} \cdot \mathrm{m}^{-2} \cdot \mathrm{d}^{-1}$. The average DLI while rooting korean lilac was 12.4 $\mathrm{mol} \cdot \mathrm{m}^{-2} \cdot \mathrm{d}^{-1}$ with a maximum instantaneous $P A R$ reading of $960 \mu \mathrm{mol} \cdot \mathrm{m}^{-2} \cdot \mathrm{s}^{-1}$. The average DLI while rooting inkberry was $2.9 \mathrm{~mol} \cdot \mathrm{m}^{-2} \cdot \mathrm{d}^{-1}$ with a maximum instantaneous $P A R$ reading of $400 \mu \mathrm{mol} \cdot \mathrm{m}^{-2} \cdot \mathrm{s}^{-1}$.

On the date of harvest for the korean lilac experiment, two cuttings per system per block were transplanted into 5 -inch plastic azalea pots (Kord, Toronto, Canada) containing a commercial peat and perlite-based growing medium (Fafard l-PV; Sun Gro Horticulture) and top-dressed with 1 tablespoon of $17 \mathrm{~N}-2.2 \mathrm{P}-$ $9.1 \mathrm{~K}$ controlled-release fertilizer (Osmocote Pro 17-5-11; Everris, Dublin, $\mathrm{OH})$. Transplanted cuttings of korean lilac were grown in an unshaded, glass-glazed greenhouse with natural photoperiod, and handwatered every $2-5 \mathrm{~d}$. The average daily temperature was $19.5{ }^{\circ} \mathrm{C}$ and DLI was $2.9 \mathrm{~mol} \cdot \mathrm{m}^{-2} \cdot \mathrm{d}^{-1}$

DATA COLleCtion AND ANALYSIS. The korean lilac cuttings were harvested from each propagation system on 23 Sept. 2016. Inkberry cuttings were harvested on 17 Dec. 2016. For each cutting, the presence or absence of roots, a subjective root rating (from $0=$ no roots to $5=$ robust rooting), number of roots, length of the longest root as measured with a ruler, and a root distribution score (roots originating from 1 to 4 quadrants of cross-sectional stem surface) were recorded. In the korean lilac experiment, eight of 10 cuttings per system per block were destructively harvested, the total number of roots were counted, and root dry weight was recorded after roots were dried for 1 week in folded paper towels placed in a room maintained at $\approx 68{ }^{\circ} \mathrm{C}$. The remaining cuttings were transplanted into a soilless medium to evaluate transplant performance, as described previously. For 
inkberry, all 10 cuttings per system per block were destructively harvested, as transplant success was not evaluated for this species.

Transplanted cuttings of korean lilac were harvested on 20 Dec. 2016. We recorded survival, counted primary roots, measured the longest root of each plant, and recorded root dry weight. Shoot data are not presented because terminal buds were endodormant and shoot growth did not occur; root data are presented because roots do not enter endodormancy and continued to grow.

Before data analysis, all subsamples per replicate system were averaged to arrive at a value for each experimental unit. We used RStudio (version 1.0.143; RStudio, Boston, MA) to analyze data by a two-way analysis of variance to account for the randomized complete block design.

\section{Results}

Cuttings of korean lilac that were propagated in the submist aeroponic systems rooted at the same percentage and earned subjective root ratings and root distribution scores that were not significantly greater than those of cuttings propagated using overhead mist (Table 1). However, cuttings propagated in the submist system had more than twice the number of primary roots and produced roots that were 2.6 times the length. Although the recorded root dry weights in submist averaged more than three times those in overhead mist, the probability value was not significant because of high variability among blocks. Among randomly selected cuttings that were transplanted to a greenhouse medium and grown for $88 \mathrm{~d}$, cuttings propagated using submist had eight times the number of primary roots, roots nearly three times the length, and root dry weights 3.7 times those of plants grown from cuttings propagated with overhead mist (Table 2). A morphological transition from aeroponics to a soilless substrate was evident in the primary roots after several months as the original aeroponic roots produced new primary root growth that was thicker and with conspicuous fine roots. Although twice as many cuttings from the submist system survived to the end of the experiment, the $P$ value for transplant survival was not significant (Table 2).

In the second study, cuttings of inkberry that were propagated in the submist aeroponic systems rooted

Table 1. Percentage rooting, root rating, root number, root length, root dry weight, and root distribution of semihardwood stem cuttings of korean lilac after $72 \mathrm{~d}$ in overhead mist systems and submist aeroponic systems.

\begin{tabular}{lccc}
\hline & Overhead mist & Submist & Pvalue \\
\hline Rooted $(\%)$ & 80 & 80 & 1.000 \\
Root rating $(0-5)^{\mathrm{z}}$ & 1.7 & 2.6 & 0.200 \\
Roots (no.) & 6.1 & 14.9 & 0.018 \\
Root length $(\mathrm{cm})^{\mathrm{y}}$ & 4.5 & 12.0 & 0.030 \\
Root dry weight $(\mathrm{mg})^{\mathrm{x}}$ & 18.3 & 58.3 & 0.060 \\
Root distribution $(0-4)^{\mathrm{w}}$ & 1.7 & 2.4 & 0.128 \\
\hline
\end{tabular}

${ }^{\mathrm{z}} 0$ (no roots) to 5 (robust rooting).

${ }^{y}$ Length of the longest root present on the cutting; $1 \mathrm{~cm}=0.3937$ inch.

${ }^{\mathrm{x}} \mathrm{l} \mathrm{mg}=3.5274 \times 10^{-5} \mathrm{oz}$.

${ }^{\mathrm{w}} 0$ (no roots) to 4 (all four quadrants of stem viewed in cross section with primary roots emerging).

Table 2. Percentage survival, root number, root length, and root dry weight of semihardwood stem cuttings of korean lilac rooted in overhead mist and submist systems, transplanted without acclimatization into a soilless greenhouse medium, and grown for $88 \mathrm{~d}$. Although roots continued to grow, shoots were endodormant following propagation.

\begin{tabular}{lccc}
\hline & Overhead mist & Submist & Pvalue \\
\hline Survival (\%) & 40 & 80 & 0.099 \\
Roots (no.) & 2.4 & 19.3 & 0.029 \\
Root length $(\mathrm{cm})^{\mathrm{z}}$ & 6.4 & 18.0 & 0.006 \\
Root dry weight $(\mathrm{mg})^{\mathrm{y}}$ & 59.1 & 217.9 & 0.033 \\
\hline
\end{tabular}

${ }^{\mathrm{z}}$ Length of the longest root present on the cutting; $1 \mathrm{~cm}=0.3937 \mathrm{inch}$.

${ }^{\mathrm{y}} 1 \mathrm{mg}=3.5274 \times 10^{-5} \mathrm{oz}$.

at 1.8 times the percentage $(96 \%)$ of cuttings propagated in overhead mist $(56 \%)$. Moreover, cuttings rooted in submist produced root ratings, root counts, and root lengths more than three times those of cuttings propagated in the overhead mist systems (Table 3). Finally, cuttings propagated using submist produced roots of 10 times the dry weight of cuttings propagated using overhead mist.

\section{Discussion}

Our results demonstrate that submist aeroponics may be a viable alternative to overhead mist for propagation of semihardwood stem cuttings of woody nursery crops. Comparisons between the two systems for korean lilac and inkberry demonstrate several advantages to the use of submist in measures of rooting (Tables 1 and 3 ). Moreover, korean lilac transplanted into containers of soilless media showed that acclimatization from submist to a solid medium was successful (Table 2).

These results are consistent with those of Peterson et al. (2018), who investigated several propagation systems as alternatives to overhead mist using coleus as a study crop. Submist produced superior measures of rooting compared with overhead mist, subirrigation, and subfog systems for the propagation of coleus by stem cuttings (Peterson et al., 2018). Maroya et al. (2014) also propagated winged yam (Dioscorea alata) and white yam (Dioscorea rotundata) using a submist aeroponic system, and Mehandru et al. (2014) found that an aeroponic system produced highquality root systems on stem cuttings of paimpa (Caralluma edulis), jeewanti (Leptadenia reticulata), and dambel (Tylophora indica), medicinal herbs in the milkweed family (Asclepiadaceae). Although research on the propagation of woody ornamentals in aeroponic systems is scarce, Soffer and Burger (1989) found that stem cuttings of weeping fig (Ficus benjamina) rooted in an aero-hydroponic system produced roots superior to those obtained by using overhead mist.

Providing water only to the basal ends of stem cuttings, without wetting the leaves, can be as effective as, or more effective than, the use of overhead mist (Peterson et al., 2018; Soffer and Burger, 1989; Zhang and Graves, 1995). However, it is not 
Table 3. Percentage rooting, root rating, root number, root length, root dry weight, and root distribution of semihardwood stem cuttings of inkberry after $64 \mathrm{~d}$ in overhead mist systems and submist aeroponic systems.

\begin{tabular}{lccr}
\hline & Overhead mist & Submist & Pvalue \\
\hline Rooted $(\%)$ & 54 & 96 & 0.006 \\
Root rating $(0-5)^{\mathrm{z}}$ & 0.7 & 2.4 & $<0.001$ \\
Roots (no.) & 18.1 & 59.6 & 0.023 \\
Root length $(\mathrm{cm})^{\mathrm{y}}$ & 2.1 & 7.6 & 0.002 \\
Root dry weight $(\mathrm{mg})^{\mathrm{x}}$ & 6.8 & 70.5 & $<0.001$ \\
Root distribution $(0-4)^{\mathrm{w}}$ & 2.1 & 3.8 & 0.005 \\
\hline
\end{tabular}

${ }^{\mathrm{z}} 0$ (no roots) to 5 (robust rooting).

${ }^{\mathrm{y}}$ Length of the longest root present on the cutting; $1 \mathrm{~cm}=0.3937$ inch

${ }^{\mathrm{x}} \mathrm{l} \mathrm{mg}=3.5274 \times 10^{-5} \mathrm{oz}$.

${ }^{\mathrm{w}} 0$ (no roots) to 4 (all four quadrants of stem viewed in cross section with primary roots emerging).

clear what physiological factors in this study are responsible for the superior measures of rooting (Tables 1 and 3 ) observed for both species in submist compared with overhead mist. For example, temperature or oxygen concentration in the rooting zone, degree of water stress, or rate of photosynthesis in the cuttings all might govern biological reactions necessary for adventitious root formation and/or subsequent root elongation (LeBude et al., 2004; Rapaka et al., 2005; Tombesi et al., 2015). The degree to which overhead mist and submist systems differ in these parameters is not known, and could be the subject of future investigations. Moreover, the sheer number of environmental parameters to be optimized in a propagation system leaves open the possibility that other overhead mist systems might have performed more favorably in comparison with the submist systems.

To be useful for commercial nursery production, aeroponic propagation systems must produce plants with roots that transition effectively to solid substrates. In our experience, this does not seem to be a problem among cuttings propagated in submist systems. Peterson et al. (2018) found that coleus transitioned effectively to a solid substrate without acclimatization. Likewise, cuttings of korean lilac propagated for this work established well in a soilless substrate without acclimatization, continued to produce roots, and had final root weights greater than those of cuttings rooted in overhead mist systems before transplantation to a soilless medium (Table 2 ). These results are similar to those of Mehandru et al. (2014), in which cuttings of three herbs in the milkweed family that were rooted in aeroponics acclimatized readily to soil.

In light of our results, several additional avenues of research seem to be worth considering. For example, to what extent are the measures of rooting with korean lilac and inkberry generalizable to other woody species, including hard-to-root plants? What factor(s) contribute to differential measures of rooting between submist and overhead mist systems used in our experiments? How do roots produced using submist differ anatomically and morphologically from those produced using overhead mist, and are such root systems acceptable following the propagation phase of the nursery production schedule? Do cuttings rooted using submist overwinter adequately as bare-root plants in cold storage facilities if not transplanted until the spring?

\section{Literature cited}

Dirr, M.A. and C.W. Heuser, Jr. 2006. The reference manual of woody plant propagation. Timber Press, Portland, OR.
Hartmann, H.T., D.E. Kester, F.T. Davies, and R.L. Geneve. 2011. Hartmann and Kester's plant propagation: Principles and practices. 8th ed. Prentice Hall, Upper Saddle River, NJ.

LeBude, A.V., B. Goldfarb, F.A. Blazich, F.C. Wise, and J. Frampton. 2004. Mist, substrate water potential and cutting water potential influence rooting of stem cuttings of loblolly pine. Tree Physiol. 24: 823-831.

Maroya, N., M. Balogun, R. Asiedu, B. Aighewi, P. Lava Kuma, and J. Augusto. 2014. Yam propagation using 'aeroponics' technology. Annu. Res. Rev. Biol. 4:38943903.

Mehandru, P., N.S. Shekhawat, M.K. Rai, V. Kataria, and H.S. Gehlot. 2014. Evaluation of aeroponics for clonal propagation of Caralluma edulis, Leptadenia reticulata, and Tylophora indica-Three threatened medicinal Asclepiads. Physiol. Mol. Biol. Plants 20:365-373.

Peterson, B.J., O. Sanchez, S.E. Burnett, and D.J. Hayes. 2018. Comparison of four systems for propagation of coleus by stem cuttings. HortTechnology 28:143-148.

Preece, J.E. 2003. A century of progress with vegetative plant propagation. HortScience 38:1015-1025.

Rapaka, V.K., B. Bessler, M. Schreiner, and U. Druege. 2005. Interplay between initial carbohydrate availability, current photosynthesis, and adventitious root formation in Pelargonium cuttings. Plant Sci. 168:1547-1560.

Soffer, H. and D.W. Burger. 1989. Plant propagation using an aero-hydroponics system. HortScience 24:154.

Tombesi, S., A. Palliotti, S. Poni, and D. Farinelli. 2015. Influence of light and shoot development stage on leaf photosynthesis and carbohydrate status during the adventitious root formation in cuttings of Corylus avellana L. Front. Plant Sci. 6:973

Zhang, H. and W.R. Graves. 1995. Subirrigation to root stem cuttings: Comparison to intermittent mist and influence of fertilization. HortTechnology 5:265-268. 